\title{
Circulating immune cell populations related to primary breast cancer, surgical removal, and radiotherapy revealed by flow cytometry analysis
}

Sarah Cattin ${ }^{1}$, Benoît Fellay ${ }^{2}$, Antonello Calderoni ${ }^{3}$, Alexandre Christinat ${ }^{3}$, Laura Negretti ${ }^{4}$, Maira Biggiogero ${ }^{4,5}$, Alberto Badellino ${ }^{4,5}$, Anne-Lise Schneider $^{6}$, Pelagia Tsoutsou ${ }^{6,7}$, Alessandra Franzetti Pellanda ${ }^{4,5+}$ and Curzio Rüegg ${ }^{1 * \dagger}$ (D)

\begin{abstract}
Background: Advanced breast cancer (BC) impact immune cells in the blood but whether such effects may reflect the presence of early $B C$ and its therapeutic management remains elusive.

Methods: To address this question, we used multiparametric flow cytometry to analyze circulating leukocytes in patients with early BC $(n=13)$ at the time of diagnosis, after surgery, and after adjuvant radiotherapy, compared to healthy individuals. Data were analyzed using a minimally supervised approach based on FlowSOM algorithm and validated manually.
\end{abstract}

Results: At the time of diagnosis, $B C$ patients have an increased frequency of $C D 117^{+} C D 11 b^{+}$granulocytes, which was significantly reduced after tumor removal. Adjuvant radiotherapy increased the frequency of $C D 45 R^{+}$memory $C D 4^{+} T$ cells and $\mathrm{CD}^{+}{ }^{+}$regulatory $T$ cells. FlowSOM algorithm analysis revealed several unanticipated populations, including cells negative for all markers tested, $\mathrm{CD} 11 \mathrm{~b}^{+} \mathrm{CD} 15^{\text {low }}, \mathrm{CD}^{+} \mathrm{CD}^{-} \mathrm{CD}^{-}, \mathrm{CD}^{+} \mathrm{CD}^{+} \mathrm{CD}^{+}$, and $\mathrm{CD}^{+} \mathrm{CD} 8^{+} \mathrm{CD} 127^{+} \mathrm{CD} 45 \mathrm{RO}^{+}$cells, associated with $\mathrm{BC}$ or radiotherapy.

Conclusions: This study revealed changes in blood leukocytes associated with primary BC, surgical removal, and adjuvant radiotherapy. Specifically, it identified increased levels of $C D 117^{+}$granulocytes, memory, and regulatory CD4 $4^{+}$ $\mathrm{T}$ cells as potential biomarkers of BC and radiotherapy, respectively. Importantly, the study demonstrates the value of unsupervised analysis of complex flow cytometry data to unravel new cell populations of potential clinical relevance.

Keywords: Breast cancer, Radiotherapy, Granulocytes, Monocytes, CD117, FlowJo, Unsupervised analysis, Biomarker

\footnotetext{
* Correspondence: curzio.ruegg@unifr.ch

${ }^{\dagger}$ Alessandra Franzetti Pellanda and Curzio Rüegg contributed equally to this work.

'Pathology, Department of Oncology, Microbiology and Immunology,

Faculty of Science and Medicine, University of Fribourg, $\mathrm{CH}-1700$ Fribourg, Switzerland

Full list of author information is available at the end of the article
}

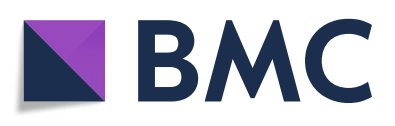

(- The Author(s). 2021 Open Access This article is licensed under a Creative Commons Attribution 4.0 International License, which permits use, sharing, adaptation, distribution and reproduction in any medium or format, as long as you give appropriate credit to the original author(s) and the source, provide a link to the Creative Commons licence, and indicate if changes were made. The images or other third party material in this article are included in the article's Creative Commons licence, unless indicated otherwise in a credit line to the material. If material is not included in the article's Creative Commons licence and your intended use is not permitted by statutory regulation or exceeds the permitted use, you will need to obtain permission directly from the copyright holder. To view a copy of this licence, visit http://creativecommons.org/licenses/by/4.0/. The Creative Commons Public Domain Dedication waiver (http://creativecommons.org/publicdomain/zero/1.0/) applies to the data made available in this article, unless otherwise stated in a credit line to the data. 


\section{Background}

Breast cancer $(\mathrm{BC})$ is the most frequent cancer and the main cause of cancer-related mortality for women in industrialized countries [1]. Three clinically relevant biological BC subtypes (i.e., estrogens/progesterone receptor positive $\left(\mathrm{ER}+/ \mathrm{PR}^{+}\right)$, human epidermal growth factor receptor 2 (HER2) amplified, and triple negative) and multiple molecular subtypes (e.g., Luminal A/B, HER2, basal like, normal like) with distinct features and clinical outcomes have been defined and characterized [2-5].

Early detection and surgery in combination with adjuvant treatments tailored on biological and molecular subtypes have improved patients' survival by about $30 \%$ in the past three decades [6]. The goal of adjuvant therapy, including radiotherapy, is the eradication of tumor cells that are disseminated before diagnosis and surgery. Some of these disseminated tumor cells (DTC), however, will escape therapy and later progress to form metastases, which in most patients represent the main cause of cancer-related death. After breast-conserving surgery, radiotherapy reduces the risk of $\mathrm{BC}$ recurrence and death. Among women with operable $\mathrm{BC}$, randomized trials have demonstrated equivalent disease-free and overall survival between mastectomy and breast-conserving surgery followed by radiotherapy alone and/or hormonal, anti-HER2, or chemotherapy [7-16].

Mammography is the standard approach for the detection of asymptomatic BC [17]. In spite of its benefits in reducing $\mathrm{BC}$ specific mortality, mammography has some important limitations [18]: low specificity and sensitivity; risk of over-diagnosis; risk of inducing $\mathrm{BC}$ due to X-ray exposure, particularly in patients with defective DNA repair genes [19]; and not recommended before the age of 50 in spite of the fact that $20-25 \%$ of all BCs appear before this age. There is therefore an unmet need for complementary or alternative methods for the detection of asymptomatic, early BC [20-22]. Circulating tumor cells (CTC), cell-free tumor-derived DNA, mRNA and miRNA, proteins, autoantibodies, and metabolites are being explored as candidate blood-based biomarkers for $\mathrm{BC}$ detection, diagnosis, or monitoring, but so far none entered routine clinical practice [23-27]. Similarly, there are no effective blood-based biomarkers to actively assess patients' response to treatment and monitoring disease state after therapy. Also, the most used blood biomarker in clinical practice, CA 15-3, is not specific and sensitive in early breast cancer diagnosis [28].

Tumors, including BC, mobilize and recruit immunoinflammatory cells to their microenvironment [29-31]. Monocytic and granulocytic cells, mostly immature forms, as well as lymphocytes, contribute to cancer progression by promoting immunosuppression, angiogenesis, cancer cell survival, growth, invasion, and metastasis [32, 33]. We have previously shown that metastatic $\mathrm{BC}$ patients have elevated frequencies of $\mathrm{TIE}^{+} \mathrm{CD} 11 \mathrm{~b}^{+}$and $\mathrm{CD} 117^{+} \mathrm{CD} 11 \mathrm{~b}^{+}$leukocytes

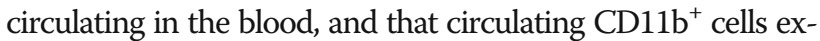
press higher mRNA levels of the M2 polarization markers CD163, ARG1, and IL-10 [34]. Treatment with paclitaxel in combination with bevacizumab decreased the frequency

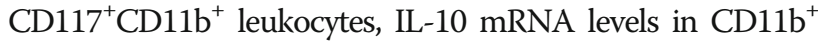
cells, and IL-10 protein in plasma. We therefore considered that blood circulating leukocytes, or sub-population, thereof, may reflect cancer-relevant immuno-inflammatory events that may be further explored as BC-associated biomarkers.

Here, we analyzed the phenotype of blood leukocytes of patients with early $\mathrm{BC}$ at time of diagnosis, after surgery, and after adjuvant radiotherapy (RTX), relative to healthy donors (HD), using flow cytometry, and a minimally supervised analytical approach based on FlowSOM algorithm and manual validation. We identified with both approaches cell populations associated with the presence of a primary $\mathrm{BC}$, tumor removal, and adjuvant radiotherapy. These results indicate that phenotypical analysis of peripheral blood leukocytes, with a minimally supervised analytical approach, may be a clinically-relevant strategy for the identification of cellular biomarkers for BC detection and therapy monitoring.

\section{Materials and methods}

\section{Patients and clinical study}

The study was approved by the Cantonal ethic commission for human research on Humans of Canton Ticino (CE 2967) and extended to Vaud-Fribourg-Neuchâtel, Switzerland. The study includes 13 female patients (Table 1) who were diagnosed with primary, nonmetastatic BC (stage T1-4, N0-N1, M0,). All patients underwent conservative surgery and received standard fractionated adjuvant radiotherapy (2 Gy per session, total dose : $50+10 \mathrm{~Gy}$ ). For the analysis at time of primary detection, only 11 patients were included for comparison with 11 age-matched healthy donors (HDs). Blood samples were collected at the following timepoints (Fig. 3): after diagnosis was confirmed histologically but before surgery (Sample 0); after surgery the day of radiotherapy start (immediately before first irradiation, Sample 1); at the last day of radiotherapy (6 weeks after starting radiotherapy, Sample 2); and 6-8 weeks after the end of the radiotherapy (for the majority to the patients this was 12 weeks after starting radiotherapy, Sample 3). All Patients and HDs gave written informed consent before study entry. Patients were recruited before surgery at Clinica Luganese Moncucco, Lugano, and at Hôpital Neuchâtelois, La Chaux-de-Fonds, once diagnosis was histologically confirmed. Mean age for cancer patients was 60.6 years (all patients were between 43 and 73 years old). HDs were recruited along the study, based on the following criteria: age-matched relative to $\mathrm{BC}$ patients, no regular medications in the last 6 months, no 
Table 1 Clinical-pathological data of breast cancer patients included in the study

\begin{tabular}{|c|c|c|c|c|c|c|c|c|c|}
\hline Patient number & Age & ER (\%) & PR (\%) & HER2 (+/-) & Ki67 (\%) & Grade & Tumor size & LN mets & Anti-hormonal therapy \\
\hline 1 & 62 & 95 & 70 & - & 5 & 1 & pT1b & $\mathrm{pN1a}$ & - \\
\hline 2 & 58 & 95 & 95 & - & 10 & 2 & $\mathrm{~T} 1 \mathrm{~b}$ & No & - \\
\hline 3 & 50 & 100 & 100 & + & 5 & 1 & pT1 & pNO & Tamoxifen \\
\hline 4 & 73 & 95 & 2 & - & 25 & 2 & pT2 & pN1a & - \\
\hline 5 & 49 & 90 & 80 & - & 10 & 2 & $\mathrm{~T} 1 \mathrm{~b}$ & $\mathrm{pNO}$ & Tamoxifen \\
\hline 6 & 69 & 100 & 100 & - & 15 & 2 & pT1a & pNo & Tamoxifen \\
\hline 7 & 53 & 95 & 60 & - & 10 & 2 & pT1c & pNO & Letrozole \\
\hline 8 & 73 & 100 & 0 & - & 20 & na & pT1c & pNo & Tamoxifen \\
\hline 9 & 67 & 90 & 80 & - & 5 & 1 & pT1b & pNo & Tamoxifen \\
\hline 10 & 66 & 100 & 100 & - & 5 & 2 & pT1c & $\mathrm{pNO}$ & Letrozole \\
\hline 11 & 64 & 95 & 80 & - & 10 & 1 & pT1b & $\mathrm{pNO}$ & Letrozole \\
\hline 12 & 61 & 80 & 100 & - & 10 & 2 & pT1b & $\mathrm{pNO}$ & Anastrozole \\
\hline 13 & 43 & 95 & 95 & - & 10 & 2 & pT1c & $\mathrm{pNO}$ & Tamoxifen \\
\hline
\end{tabular}

Patient's demographics, tumor subtype, grade, stage (pT and pN), and anti-hormonal treatment after conservative surgery. ER (\%), estrogen receptor expression in percent; PR (\%), progesterone receptor expression in percent; HER2 ( \pm ), overexpression of HER-2; Ki67 (\%), fraction of cancer cells positive for Ki67 expression

previous cancer diagnosis, no chronic diseases, and normal blood analyses at time of recruitment.

\section{Blood processing}

Twenty milliliters of peripheral venous blood was collected using BD Vacutainer Blood Collection EDTA Tubes (Becton Dickinson, Franklin Lakes, NJ, USA) following the manufacturer's instructions and immediately shipped by courier at room temperature to the laboratory. All analyses were performed within $24 \mathrm{~h}$ after blood collection. Antibody staining was performed in whole blood. Plasma and total leukocytes were isolated from the remaining blood using BD Vacutainer ${ }^{\circ} \mathrm{CPT}^{\mathrm{Tx}}$ Cell Preparation Tube (Becton Dickinson) with sodium heparin following the manufacturer's instructions. Plasma fraction was frozen at $-80{ }^{\circ} \mathrm{C}$ and isolated leukocytes were lysed in RA1 lysis buffer (Macherey-Nagel, Düren, Deutschland) and stored at $-80^{\circ} \mathrm{C}$.

\section{Flow cytometry}

Whole blood stainings were performed within $24 \mathrm{~h}$ after blood collection. Leukocytes were counted using CellDyn Sapphire Hematology System (Abbott Diagnostics, Chicago, IL, USA). For staining, 1 million cells per tube were used based on direct blood cell count. Directly labeled antibodies were added to whole blood and incubated for $20 \mathrm{~min}$ at $4{ }^{\circ} \mathrm{C}$, followed by $10 \mathrm{~min}$ red-bloodcells lysis (Bühlmann Laboratories, Schönenbuch, Switzerland) and subsequently washed using cold PBS. All anti-human antibodies were used at the concentrations recommended by the manufacturer: anti-CD15PeCy7 (clone HI98), anti-CD14-Pe (clone M $\$ \mathrm{P} 9$ ), antiCD163-FITC (clone GHI/61), anti-CD11b-BV510 (clone ICRF44), anti-CD33-V450 (clone WM53), anti-CD64-
APCH7 (clone 10.1), anti-CD117-APC (clone YB5.B8), anti-CD45RA-PeCy7 (clone HI100), anti-CD25-Pe (clone M-A251), anti-CD4-FITC (clone RPA-T4), anti-CD8V500 (clone SK1), anti-CD45RO-BV421 (clone UCHL1), anti-CD3-APCH7 (clone SK7), and CD127-Alexa Fluor 647 (clone HIL-7R-M21) and 7AAD (all from Becton Dickinson). BD FACSCanto II (Becton Dickinson) instrument was used to analyze samples and FlowJo 10.6.2 (Treestar Inc., Ashland, OR, USA) software and several software plugins (FlowCLEAN, downsample_V3, FlowSOM, tSNE) were used to analyze all data.

\section{Reverse transcription real-time PCR (RT-qPCR)}

Total mRNA from total white blood cells was extracted using the NucleoSpin RNA kit from Macherey-Nagel following the manufacturer's instructions (Düren, Germany). The purity and quantity of all RNA samples were examined by NanoDrop (Witec AG, Luzern, Switzerland). Total RNA was retro-transcribed using M-MLV reverse transcriptase kit following the manufacturer's instructions (ThermoFisher Scientific, Waltham, Massachusetts, USA) using $500 \mathrm{ng}$ of total RNA. cDNA was subjected to amplification by real-time qPCR with the StepOne SYBR System (Life Technologies) using the following primer pairs (Eurofins Genomics, Huntsville, $\mathrm{AL}, \mathrm{USA}$ ) at the indicated hybridization temperatures: GAPDH $58{ }^{\circ} \mathrm{C}$ (Fw-TCTTCTTTTGCGTCGCCAGC, RevGATTTTGGAGGGATCTCGCTCCT), ARG1 $58{ }^{\circ} \mathrm{C}$ (FwGGAGTCATCTGGGTGGATGC, Rev-CTGGCACATCG GGAATCTTTC), IL-10 $58{ }^{\circ} \mathrm{C}$ (Fw-CGAGATGCCTTCAG CAGAGT, Rev-AATCGATGACAGCGCCGTAG), CD117 $57{ }^{\circ} \mathrm{C}$ (Fw-GATTATCCCAAGTCTGAGAATGAA, RevCGTCAGAATTGGACACTAGGA), FN1 $52{ }^{\circ} \mathrm{C}$ (Fw- ACT TCGACAGGACCACTTGA, Rev-TCAAATTGGAGATT 
CATGGGA). Real-time PCR data were then analyzed using the comparative Ct method [35].

\section{Statistical analysis}

Acquired data were analyzed and graphics were generated using Prism Software (GraphPad, La Jolla, CA, USA). Samples with incomplete staining due to technical problems during the antibody staining process or during acquisition were excluded from the statistical analysis. Statistical comparisons between cancer patients and healthy donors were performed by $\mathrm{T}$ test assuming nonhomogenous variance. Normality distribution of the samples was checked in case of significance and, if nonGaussian, a Mann-Whitney replaced the $\mathrm{T}$ test results. Statistical comparisons of all time-points to observe the effect of radiotherapy were performed by one-way ANOVA assuming non-homogenous variance using Tukey correction. Normality distribution of the samples was checked in case of significance and, if non-Gaussian, a Kruskal-Wallis assay replaced the ANOVA results. Results were considered to be significant from $\mathrm{p}<0.05$. In the figures, the various $\mathrm{p}$ values thresholds are presented as follows: $\leq 0.05=*, \leq 0.01=* * ;, \leq 0.001=* \% * 0.0001=* * * * *$.

\section{Results}

Increased frequency of $\mathrm{CD} 117^{+} \mathrm{CD} 11 \mathrm{~b}^{+}$granulocytes in the peripheral blood of patients with newly diagnosed non-metastatic BC

Based on previous observations made in metastatic $\mathrm{BC}$ patients [34], we hypothesized that an increased frequency

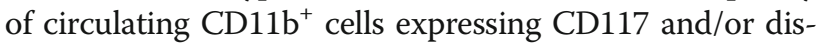
playing a M2 activation phenotype may also occur in patients with early BC. To test this hypothesis, we monitored the frequency of leukocyte populations in the blood of 11 non-metastatic BC patients (cT1-4, N0-1, M0) (Table 1) at time of diagnosis using flow cytometry. Aged-matched women without $\mathrm{BC}$ served as the control population (healthy donors (HDs)). Monocytes were defined as $\mathrm{CD} 11 \mathrm{~b}^{+} \mathrm{CD} 33^{+} \mathrm{CD} 14^{\text {high }} \mathrm{CD} 15^{-}$and granulocytes as $\mathrm{CD} 11 \mathrm{~b}^{+} \mathrm{CD} 33^{+} \mathrm{CD} 14^{\text {low }} \mathrm{CD} 15^{+}$cells (Supplementary Figure S1). Due to limitations at acquisition, we could not add additional markers to further characterize these cell populations. In both cell populations, we monitored the expression of CD117 (cKit), the receptor for Kit-ligand/ stem cell factor widely present in hematopoietic progenitor cells [36, 37], and CD163, a M2 polarization marker in monocytes [38]. In order to avoid investigator-associated biases and variability in the results inherent to supervised manual analysis of flow cytometry data, we develop a minimally supervised, standardized analytical workflow based on the FlowSOM algorithm (Supplementary Figure S2), in complement to conventional manual gating and supervised analysis.
Cells clusters revealed by standardized analytical workflow were considered of interest when their frequency was more than $10 \%$ different between HDs and cancer patients. Some of the 14 analyzed clusters corresponded to non-standard populations, for example, those negative for all tested markers or expressing unanticipated marker combinations (Fig. 1A-C). These populations would have been missed by conventional supervised gating and analysis driven by the marker combination of interest. Interestingly, we observed a significant increase in the frequency of $\mathrm{CD} 117^{+}$cells among the circulating granulocytic population in cancer patients relative to HDs (Fig. 1D). Patients over 61 years of age, but not HDs, had a non-significant trend toward having more circulating $\mathrm{CD} 117^{+}$cells compared to younger patients (less than 55 years old) (not shown).

We observed a similar (but non-significant) trend in the frequency of monocytic cells, albeit at lower frequency. In addition, the frequencies of some nonclassical cell populations, such as those expressing none of the markers of interest (Cluster 13 and 3) or a $\mathrm{CD}_{11} \mathrm{~b}^{+} \mathrm{CD} 15^{\text {low }}$ cell population (Cluster $22+9$ ), were significantly different between $\mathrm{BC}$ patients and HDs (Fig. 1E, F). No significant changes were observed for $\mathrm{CD}_{163}{ }^{+}$cells in both granulocytes and monocytes cell populations (Supplementary Figure S3). No effect related to the age of the patients or HDs was observed in this small cohort (not shown).

\section{Non-standard CD3-expressing cells are present with increased frequency in the peripheral blood of newly diagnosed $B C$ patients}

In parallel, we monitored the presence of selected lymphocyte populations in both groups. By conventional supervised analysis, we observed no differences in classical $\mathrm{CD}^{+} \mathrm{CD} 4^{+}$ $\mathrm{T}$ cells, $\mathrm{CD}^{+} \mathrm{CD}^{+} \mathrm{T}$ cells, and $\mathrm{CD} 3^{+} \mathrm{CD} 4^{+} \mathrm{CD} 25^{+} \mathrm{CD} 127^{-}$ regulatory $\mathrm{T}$ cells (Tregs). Likewise, we observed no changes in the frequency of memory $\left(\mathrm{CD} 45 \mathrm{RO}^{+} \mathrm{CD} 45 \mathrm{RA}^{-}\right)$or naïve $\left(\mathrm{CD} 45 \mathrm{RA}^{+} \mathrm{CD} 45 \mathrm{RO}^{-}\right) \mathrm{T}$ cells within the same lymphocyte populations (Supplementary Figure S4).

In contrast, FlowSOM analysis performed on lymphocytes revealed 21 populations that were more than $10 \%$ differentially represented between HDs and cancer patients (Fig. 2A-C). A population of cells of the size of lymphocytes, but negative for CD3, CD4, or CD8 expression (Cluster $24+29$ ), was significantly less represented in cancer patients relative to $\mathrm{HDs}$. $\mathrm{CD}^{+}{ }^{+} \mathrm{CD}^{+} \mathrm{T}$ cells expressing CD127 and CD45RO markers (Cluster $3+7$ ) are present at a significantly higher frequency in cancer patients. A cell cluster expressing CD3, but not CD4 or CD8 (Cluster 20), was observed at higher frequency in cancer patients relative to HDs (Fig. 2D-F).

Taken together, these results reveal an increased frequency of peripheral blood $\mathrm{CD} 117^{+}$granulocytes in 
A

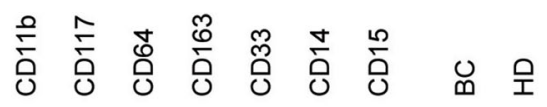

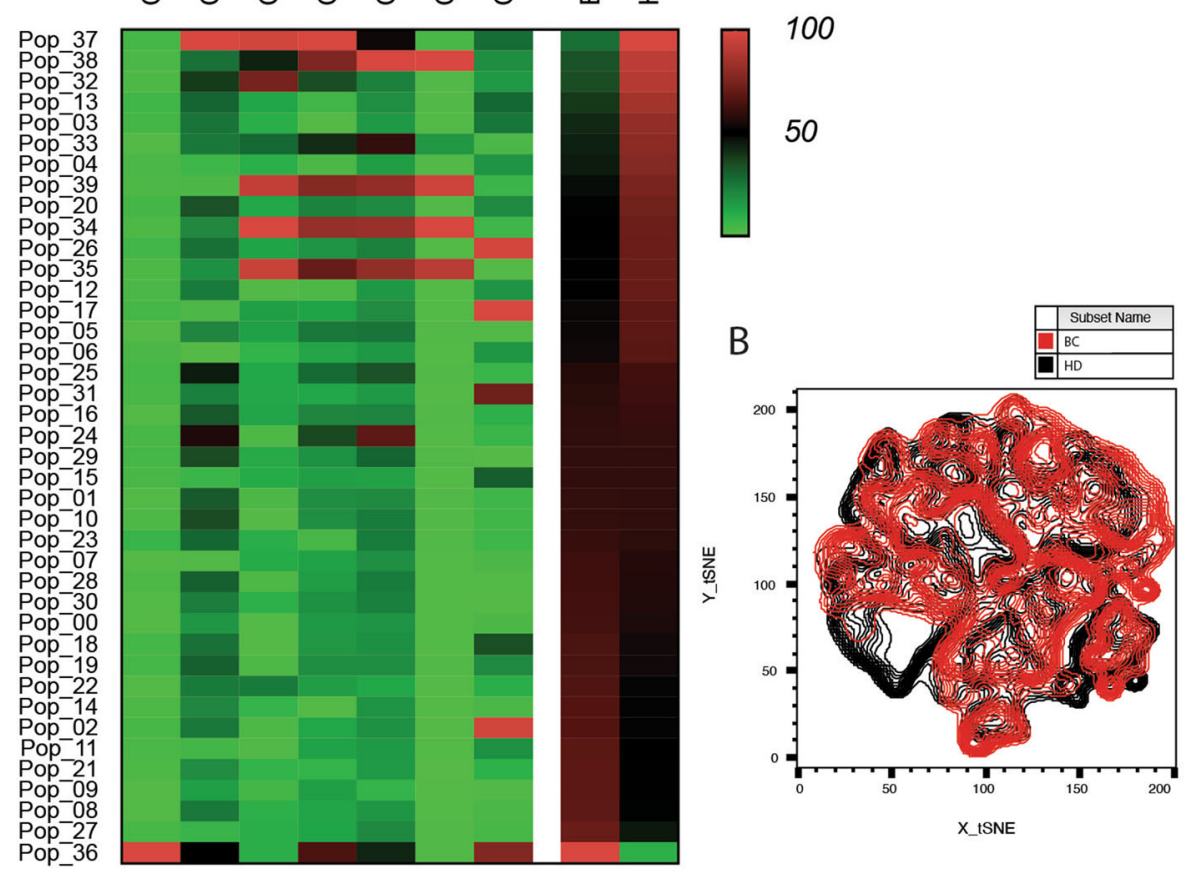

C
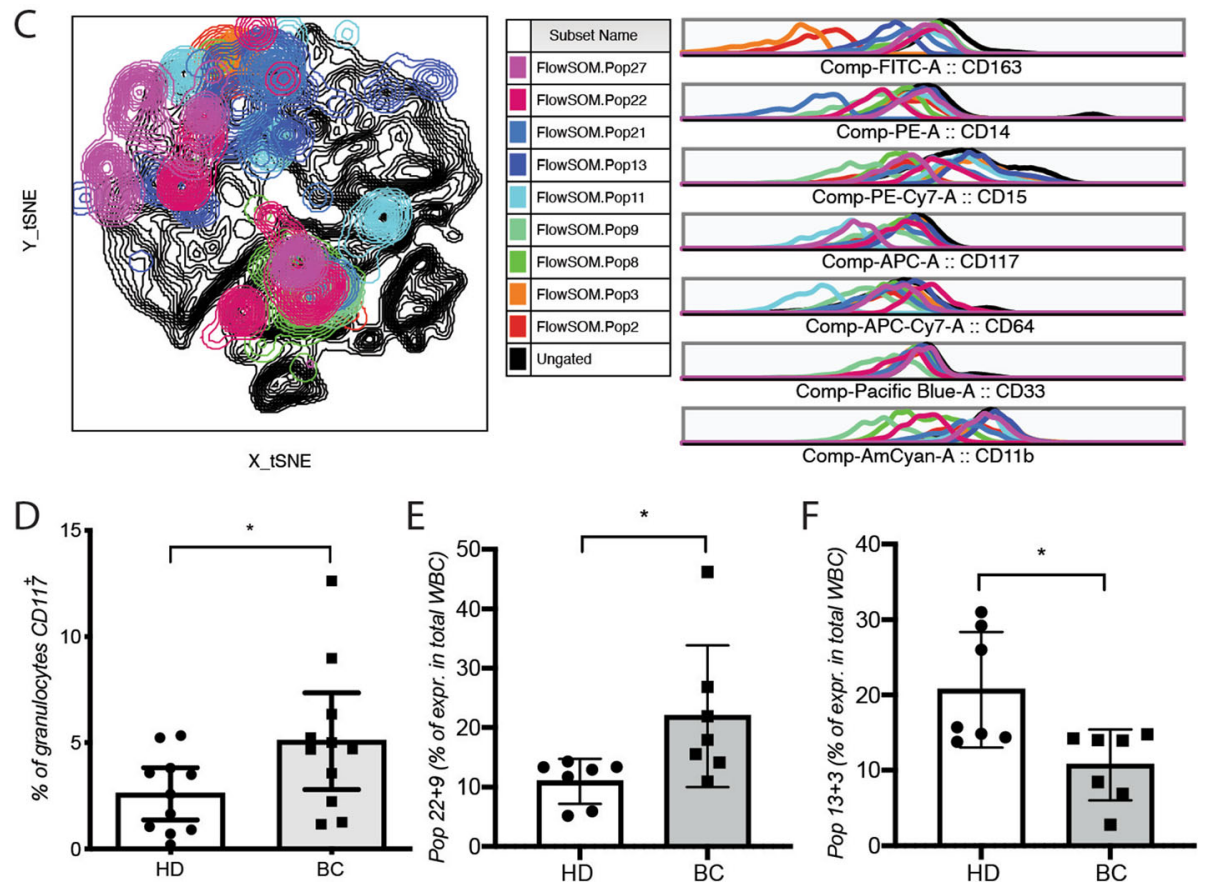

Fig. 1 Altered frequency of circulating monocytic populations in cancer patients. A Heat map of the FlowSOM clustering between breast cancer patients (BC) and healthy donors (HD). tSNE visualization of $\mathbf{B}$ the monocytic expression profile and $\mathbf{C}$ the differentially expressed clusters in the blood of breast cancer patients at the time of the first diagnosis vs healthy donors. Frequency of $\mathbf{D} C D 117^{+}$granulocytic population, and the atypical populations $\mathbf{E} 22+9$ and $\mathbf{F} 13+3$ at the same timing. WBC, white blood cells. Cell analysis and quantification were performed by flow cytometry with FlowJo software and results are represented as mean values +/- SD 


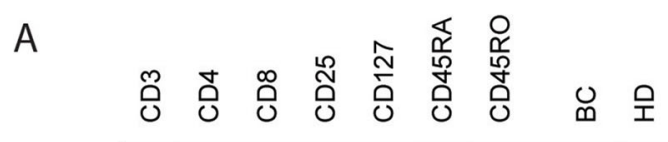

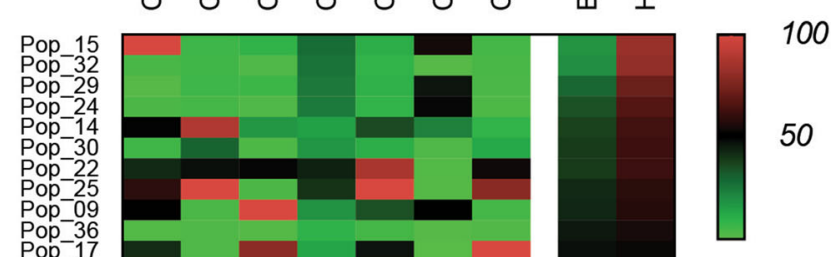

Pop_36

Pop -16

Pop_16

Pop_38

Pop-33

Pop-26

Pop_37

Pop-19

Pop_10

Pop_18

Pop_39

Pop_01

Pop_27

Pop_06

Pop_31

Pop_05

Pop_21

Pop_04

Pop_11

Pop_23

Pop_02

Pop_08

Pop_03

Pop_20

Pop_28

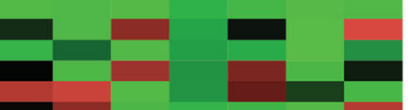

C
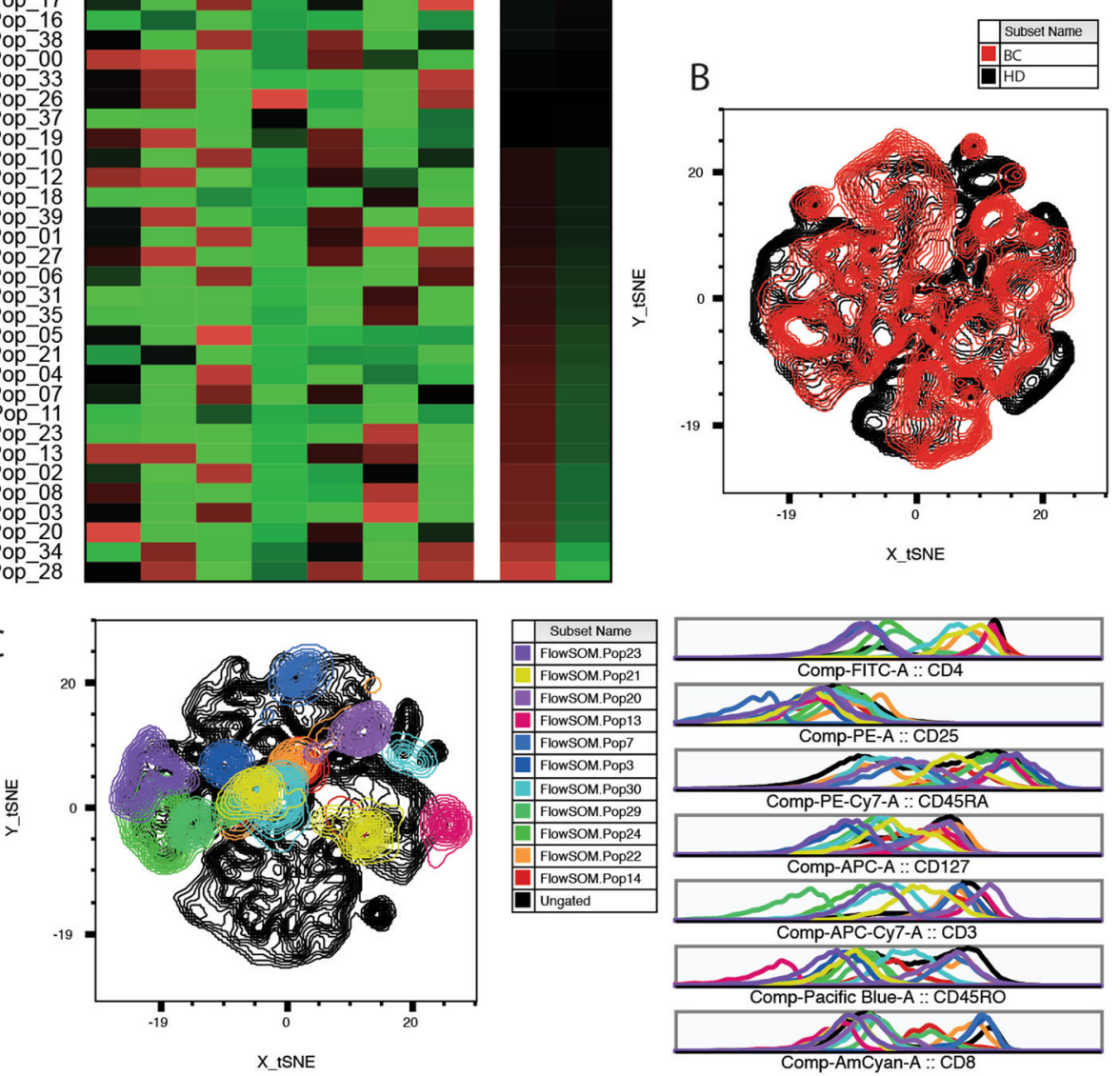

D
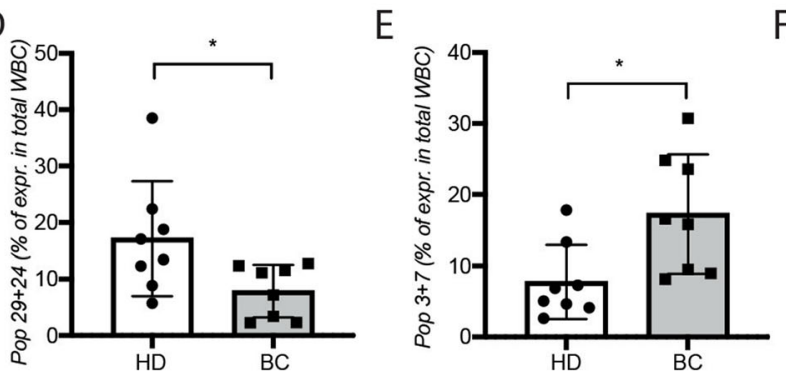

F

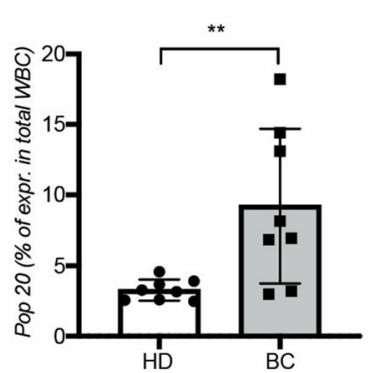

Fig. 2 Altered frequency of circulating lymphocyte populations in cancer patients. A Heat map of the FlowSOM clustering between breast cancer patients (BC) and healthy donors (HD). tSNE visualization of $\mathbf{B}$ the lymphocyte expression profile and $\mathbf{C}$ the differentially expressed clusters in the blood breast cancer patients at the time of the first diagnosis of healthy donors. Frequency of the atypical populations $\mathbf{D} 29+24, \mathbf{E} 3+7$, and $\mathbf{F}$ 20 at the same timing. WBC, white blood cells. Cell analysis and quantification were performed by flow cytometry with FlowJo software and results are represented as mean values $+/-$ SD 
non-metastatic $\mathrm{BC}$ patients at time of diagnosis, as well as significant changes in the frequency of myeloid and lymphocytic cell populations expressing unconventional marker combinations. They also demonstrate that FlowSOM-based analysis can identify cell populations that would have been missed by supervised analysis.

\section{No detectable changes in the expression level of}

\section{transcripts for $\mathrm{M} 2$ polarization markers}

We previously reported that transcripts of M2-associated genes were expressed at higher levels circulating $C D 11 b^{+}$ cells in metastatic $\mathrm{BC}$ patients compared to HDs (34). We therefore analyzed the expression of mRNA for CD117 and the M2 markers IL-10, fibronectin-1 (FN1), and arginase 1 (ARG1) in total leukocytes from cancer patients and HDs. No differences in expression levels were observed (Supplementary Figure S5).

\section{A proof-of-concept study to monitor the effects of} surgical tumor removal and adjuvant radiotherapy on circulating immune cells in $\mathrm{BC}$ patients

The differences observed in myelomonocytic and lymphocytic populations in $\mathrm{BC}$ patients at time of diagnosis relative to HDs raised the question whether tumor removal and/or adjuvant therapy may reverse these changes, or induce additional ones. To address this question, we performed a proof-of-concept study, by taking advantage of the fact that the investigated patients were scheduled for breast conservative tumor removal and adjuvant radiotherapy as part of their standard treatment. Adjuvant radiotherapy was selected as therapy of choice as systemic effects on the immune system have been reported [39-41], while on the other side chemotherapy was excluded in order to avoid that myelosuppressive effects induced by chemotherapy could nonspecifically impact the results [42]. To search for potential changes in cell populations in response to surgery and radiotherapy we analyzed monocytes, granulocytes, and lymphocytes at three time-points: after surgery/before radiotherapy start (1_PostOP), at the end of radiotherapy (6 weeks; 2_Post_RTX_6w) and at 6-8 weeks after the end of radiotherapy (12-14 weeks; 3 Post_RTX_12w) in 13 patients. Results were compared to values obtained at the time of diagnosis (0_PreOP) (Fig. 3).

Tumor removal increased the frequency of monocytic and granulocytic cells, but decreased $\mathrm{CD} 117^{+}$granulocytes and radiotherapy-induced changes in non-standard myeloid cell populations

Using FlowSOM workflow of analysis, we observed distinct expression profiles at the four time-points globally visualized by tSNE. Seventeen cell clusters were found highly differentially represented in one group compared to the other groups. Surprisingly, when looking at the expression profiles of each cluster of interest, the majority of them was lacking CD33 expression, suggesting that this marker may not be suitable to analyze the monocytes fraction (Fig. 4A, B).

After tumor removal and at the end of radiotherapy the frequency of both monocytes and granulocytes were significantly increased relative to values at the time of diagnosis and returned to pre-therapy levels $6-8$ weeks after the end of radiotherapy (Fig. 4C, D). Strikingly, within the granulocytic population, the fractions of CD117 expressing cells significantly decreased after tumor removal and this decrease persisted after the end of radiotherapy (Fig. 4E). Surgery had no impact on the fraction of $\mathrm{CD}_{163}{ }^{+}$granulocytic population (Fig. 4F). Radiotherapy itself had an impact on granulocytes expressing CD163, but not on granulocytes expressing CD117 (Fig. 4E, F).

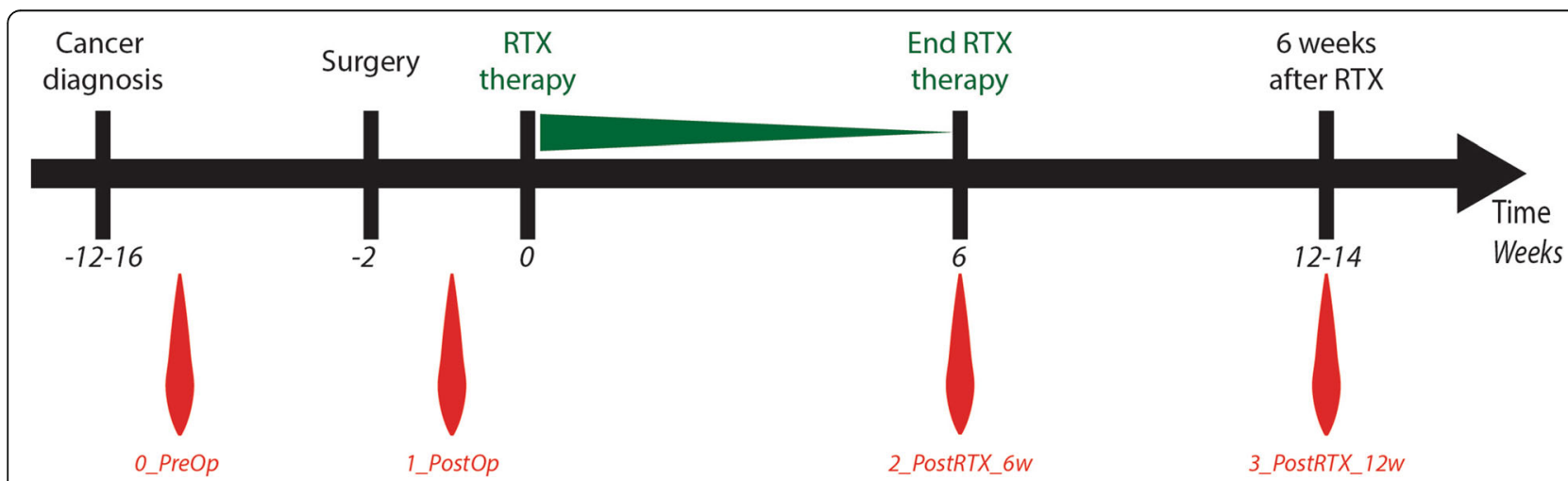

Fig. 3 Schematic representation of the radiotherapy study. Patients were enrolled after a confirmed histological diagnosis of breast cancer. All patients underwent conservative surgery and received standard fractionated adjuvant radiotherapy (2 Gy per session, total $50+10 \mathrm{~Gy}$ ). Blood samples were collected after diagnosis was confirmed histologically, but before surgery (Sample 0), after surgery; the day of starting radiotherapy (immediately before fist irradiation, Sample 1); at the last day of radiotherapy (6 weeks after starting radiotherapy, Sample 2), and 6-8 weeks after the end of the radiotherapy (for the majority to the patients this was 12 weeks after starting radiotherapy, Sample 3) 


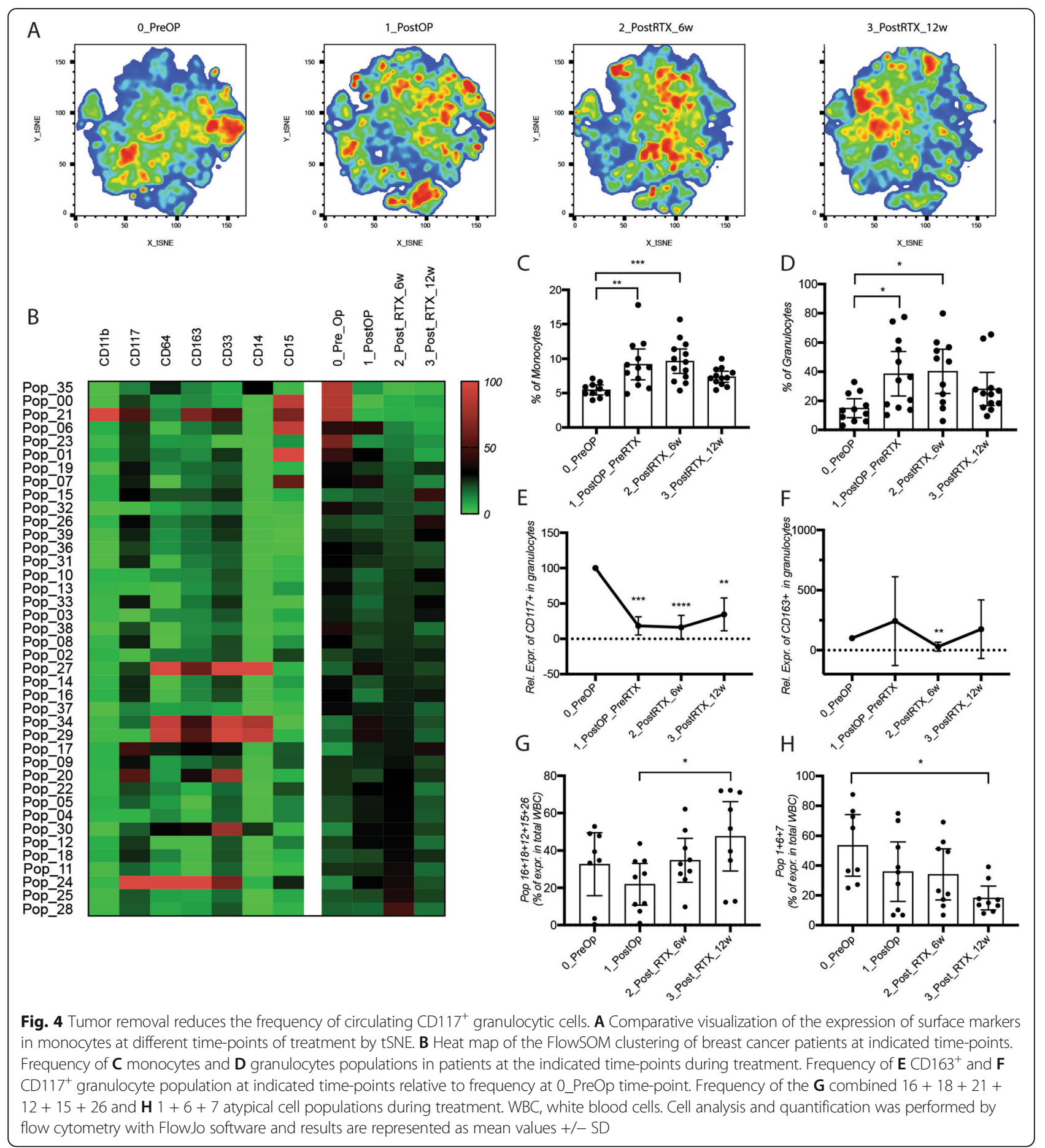

The presence of one particular cell cluster expressing only CD11b and CD15 (Pop 1, 6, and 7) clearly decreased after radiotherapy. Another population expressing CD11b but lacking expression of all tested markers significantly increased during and after radiotherapy (Pop 16, 18, 12, 15, and 26) (Fig. 4G, H). The latter observation suggests that some populations defined by non-standard marker combinations may be potentially interesting candidates to investigate further with an extended panel of markers.

Analysis of total blood leukocytes for CD117, IL-10, FN1, and ARG1 mRNA expression by RT-qPCR revealed no observable differences in their expression levels (Supplementary Figure S6). 
Adjuvant radiotherapy increased the frequency of $\mathrm{CD} 4^{+}$ memory and regulatory $\mathrm{T}$ cells, and induced changes in non-standard lymphocytic populations

Likewise, we performed unsupervised analysis of the lymphocyte populations at the three time-points after surgery and radiotherapy. Visualization by tSNE revealed distinctive changes in marker expression profiles. Eleven cell clusters were found highly differentially represented in one group compared to the other ones (Fig. 5A, B). After tumor removal, we observed highly variable effects on the frequency of $\mathrm{T}$ lymphocyte subpopulations, most of which were inconsistent and statistically non-significant.
Among the stably differentially represented clusters at the various time-points, a $\mathrm{CD}^{+}$cell population positive for $\mathrm{CD} 4$ and $\mathrm{CD} 8$ (Cluster 25), and a $\mathrm{CD} 3^{+} \mathrm{CD} 4^{+} \mathrm{CD} 127^{+} \mathrm{CD} 45 \mathrm{RO}^{+}$ population (Cluster 41) appeared at higher frequency after treatment (Fig. 5C, D). Strikingly, the frequency of this $\mathrm{CD} 45 \mathrm{RO}^{+} \mathrm{RA}^{-}$memory subset within the $\mathrm{CD3}^{+} \mathrm{CD}^{+}$ lymphocyte population was significantly and consistently increased at the end of radiotherapy and this increase was still evident 6-8 weeks later. A similar increase was also present among $\mathrm{CD}_{4}^{+}$regulatory T cells, corresponding to clusters 23 and 30, which also persisted after the end of radiotherapy (Fig. 5E-G).

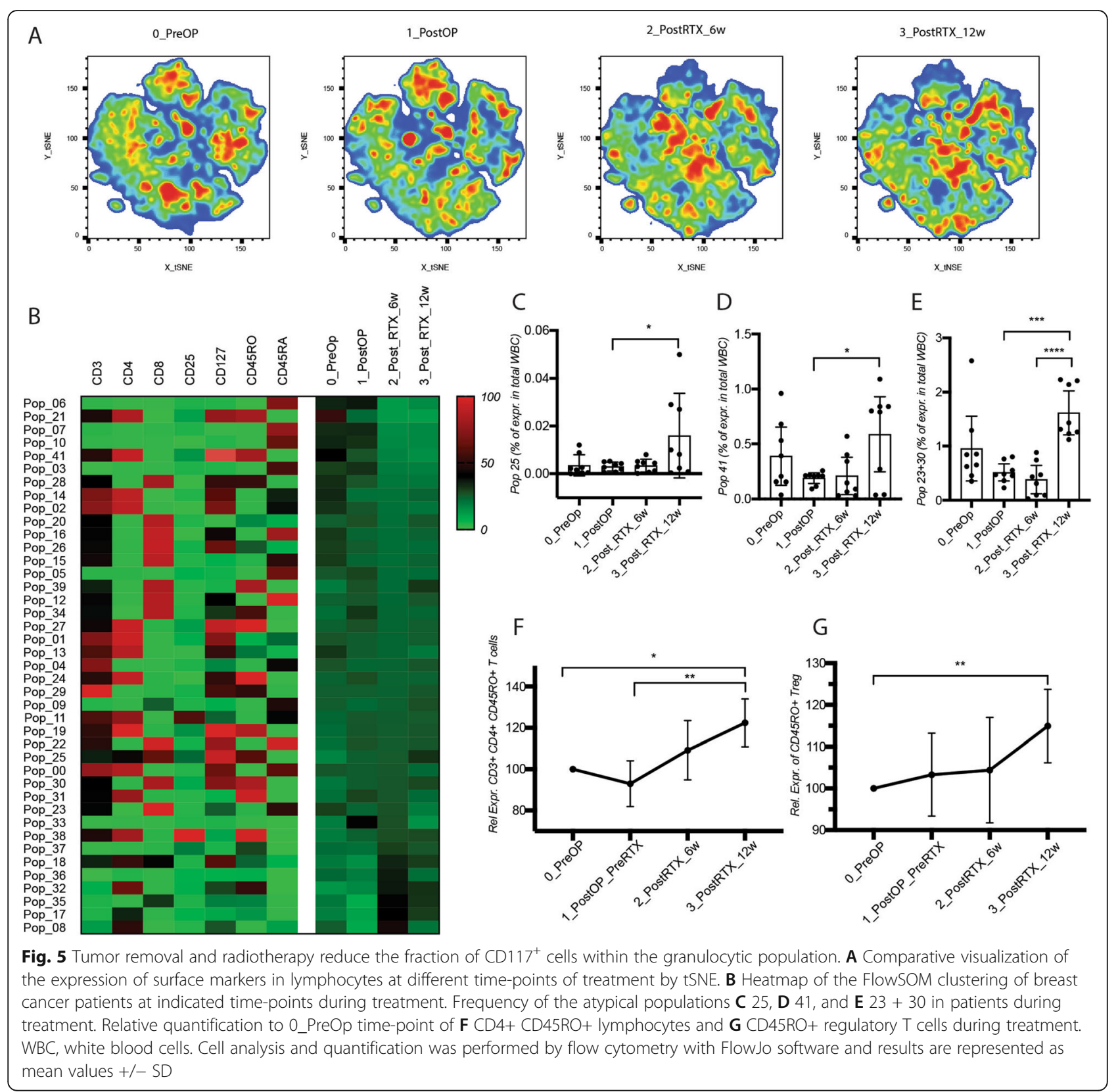




\section{Discussion}

Mammography-based screening significantly reduces BC-related mortality, but intrinsic and practical limitations call for novel screening approaches [17-20]. Blood-based biomarkers exploiting CTC, cancer-derived DNA or RNA, are being explored, but so far none reached clinical routine practice $[22,43]$. Similarly, there are no validated biomarkers for monitoring patients' response to treatment or detecting relapses before they become symptomatic.

In this study, we pursued the use of flow cytometry to analyze the phenotype and frequency of blood leukocytes in patients with non-metastatic $\mathrm{BC}$ at the time of diagnosis, after surgical tumor removal, and after adjuvant radiotherapy. Using a combination of minimally supervised (FlowSOM algorithm), and supervised (manual) analytical approaches, we report that (i) at diagnosis, BC patients have an increased frequency of circulating $\mathrm{CD}_{117^{+}}$granulocytes relative to age-matched healthy donors; (ii) surgical tumor removal causes a transient increase of monocytes and granulocytes, and a long-lasting decrease of $\mathrm{CD} 17^{+}$granulocytes; (iii) radiotherapy significantly increases $\mathrm{CD}_{45 \mathrm{R}^{+}}$memory $\mathrm{T}$ cells and $\mathrm{CD}^{+}$ Treg cells; and (iv) with the FlowSOM algorithm, we identified additional unanticipated, non-classical cell populations differentially represented between $\mathrm{HD}$ and $\mathrm{BC}$ patients and in $\mathrm{BC}$ patients in response to therapy.

Traditionally, flow cytometry results are analyzed manually, which has the potential to introduce investigatorspecific biases. To tested for this, we asked a technician expert with flow cytometry analysis but who was not involved in this project, to reanalyze the raw data and to find four specific populations of interest. Reassuringly this analysis confirmed the original results (not shown). A full reanalysis, however, is time-consuming and hard to implements in a routine (clinical) setting. As an alternative to avoid potential human biases and variability of the result, we choose to perform unsupervised, algorithm-based analyses. Also, algorithms are more effective in finding potentially interesting marker combinations. Populations of interest were then investigated more in detail manually. Here too, we performed several times the same unsupervised analysis and we could reproducibly find the same populations (not shown). This confirms the value of the approach and of the populations identified, further supporting the use of an unsupervised analysis approach to prospectively identify robust changes among complex populations.

One question that emerged during the unsupervised analysis is how to set the cutoff between samples to discriminate robust marker combinations (clusters of interest) form from unstable ones. As no standard or optimal method is defined for this kind of analyses, we tested cut-off values of $5 \%, 10 \%$, and $20 \%$. The $5 \%$ cutoff was not stringent enough, because many identified populations could not be confirmed. With a $10 \%$ cutoff, we observed a good balance between identify robust, reproducible populations, and non-interesting or unstable ones. With a $20 \%$ cutoff, we missed small but robust differences seen with 5 and $10 \%$ cutoff. We therefore decided to use the $10 \%$ cutoff.

CD117, the receptor for Kit-ligand/stem cell factor, is widely expressed in hematopoietic progenitor cells in the bone marrow, while $\mathrm{CD}_{117^{+}}$leukocytes are rarely detectable in the circulation under homeostatic conditions [36]. We have previously reported a role of $\mathrm{CD} 117^{+}$leukocytes in metastasis in the murine $4 \mathrm{~T} 1$ metastatic $\mathrm{BC}$ model [44] and the presence of $\mathrm{CD} 117^{+} \mathrm{CD} 11 \mathrm{~b}^{+}$cells in the blood of $\mathrm{mBC}$ patients [34]. Here, we observed an increased frequency of a CD $117^{+}$population among total granulocytes in the peripheral blood of non-metastatic $\mathrm{BC}$ patients at the time of diagnosis, compared to $\mathrm{HD}$. Interestingly, the frequency of $\mathrm{CD} 117^{+}$granulocytes significantly dropped upon tumor removal and remained below pre-treatment levels after radiotherapy. Thus, the increased frequency of $\mathrm{CD} 117^{+}$granulocytes may reflect the presence of the primary tumor. No changes were observed in CD117 mRNA expression in total leukocytes. This could be due to the fact that $\mathrm{CD} 117^{+}$cells are lost during leukocyte isolation for RNA extraction (flow cytometry was performed in non-separated total whole blood), or that CD117 mRNA expression has ceased upon cell mobilization (while CD117 protein persisted at the cell surface). The latter possibility is consistent with our previous observation that mobilized $\mathrm{CD}_{117^{+}}$cells adoptively transferred to a recipient mouse, rapidly became CD117 negative [44]. In contrast, the frequency of $\mathrm{CD}_{163}{ }^{+}$granulocytes remained rather constant, with only a transient decrease during radiotherapy. The implication of this decrease is unclear as CD163 expression did not significantly differ between HD and BC patients at the time of diagnosis. After surgery and radiotherapy also no change in the mRNA expression of CD117 and ARG1, FN1, IL-10 (i.e., M2 polarization markers) was observed, owing probably to the lack of enrichment of $\mathrm{CD}_{11 b^{+}}$cells for PCR analysis.

In cancer patients at the time of diagnosis, we observed a higher frequency of atypical $\mathrm{T}$ lymphocytes $\left(\mathrm{CD}^{+} \mathrm{CD}^{-} \mathrm{CD}^{-}\right)$and of a population of the size of lymphocytes lacking expression of all the tested markers. These observations suggest that some potentially interesting changes may occur in atypical $\mathrm{T}$ cells or in non- $\mathrm{T}$ cell populations such as B cells or NK cells. Strikingly, after radiotherapy, we observed a steady and significant increase of the fraction of $\mathrm{CD}_{4} 5 \mathrm{RO}^{+}$memory $\mathrm{T}$ cells within total $\mathrm{CD}_{4}^{+} \mathrm{T}$ cells and within $\mathrm{CD} 4^{+}$Treg. We also observed the increased presence of a $\mathrm{T}$ cell population expressing both CD4 and CD8 markers. This 
suggests that radiotherapy may cause $\mathrm{T}$ cell activation leading to the subsequent generation of memory $\mathrm{T}$ cell subsets. All patients included in this study had $\mathrm{ER}^{+}$cancer, and the majority $(10 / 13)$ received concomitant antihormonal treatment. We were thoughtful to the potential effect of anti-hormonal therapy and we analyzed our results by stratifying patients based on anti-hormonal therapy. No significative changes in the cell populations were observed (data not shown). However, as there were only three patients without anti-hormonal treatment, the significance of these results has to be considered with care.

There is increasing evidence that radiotherapy exerts its therapeutic effects, not only in the local treatment field, but also at distant sites (i.e., the so-called abscopal effect), at least in part, by eliciting a $\mathrm{T}$ cell immune response [39]. The recent observation that the combination of radiotherapy with immune checkpoint inhibitors in experimental models and cancer patients results in potent synergistic therapeutic effects further supports the involvement of $\mathrm{T}$ cell-dependent events and the therapeutic effects of radiotherapy [45-48]. Through experimental work and mathematical modeling, it has been proposed that anti-tumor $\mathrm{T}$ cells may be mobilized by radiotherapy toward peripheral tissues to eliminate DTC [49-51]. However, to date, there is paucity of human data demonstrating specific changes in circulating $\mathrm{T}$ lymphocytes to support such a model. Radiotherapy was reported to cause a global reduction in circulating lymphocyte subsets in patients treated for stage I-II prostate cancer [52] or to induce an increase in $\mathrm{CD}^{+}$Treg in the peripheral blood of patients with diverse solid cancers [53]. Low-dose radon therapy for chronic inflammatory diseases was shown to induce a long-lasting increase in circulating $\mathrm{T}$ cells paralleled with a reduced expression of activation markers [54]. Thus, the observed effect of adjuvant radiotherapy on memory $\mathrm{CD}^{+}{ }^{+} \mathrm{T}$ cells is novel and should be further explored in conjunction with patients' outcome, as possible biomarkers of therapy response or efficacy.

\section{Conclusion}

Taken together, this human exploratory study in early, non-metastatic $\mathrm{BC}$ revealed changes in blood leukocyte populations associated with the presence of $\mathrm{BC}$, surgical removal, and adjuvant radiotherapy. Specifically, we identified $\mathrm{CD}_{117^{+}}$granulocytes and $\mathrm{CD} 45 \mathrm{RO}^{+} \mathrm{CD} 4^{+}$ memory $\mathrm{T}$ cells correlating with the presence of the primary tumor and radiotherapy, respectively. Importantly, the study demonstrates that a minimally supervised, algorithm-based analysis of flow cytometry data is a powerful tool to reproducibly detect phenotypical changes in peripheral blood leukocytes in cancer patients. The approach also identifies non-anticipated population correlated with disease state of therapy.
These results should instigate the further investigation of peripheral blood leukocytes as a source of reliable candidate biomarkers to detect $\mathrm{BC}$, to monitor response to treatment and possibly disease progression.

\section{Abbreviations}

BC: Breast cancer; CTC: Circulating tumor cells; DTC: Disseminated tumor cells; HD: Healthy donor; Treg: Regulatory T cell; WBC: White blood cells

\section{Supplementary Information}

The online version contains supplementary material available at https://doi. org/10.1186/s13058-021-01441-8.

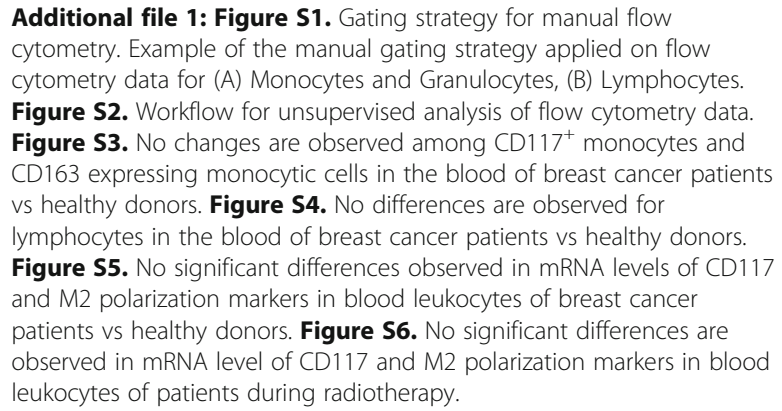

\section{Acknowledgements}

The authors wish to thank Dr. Chiara Secondini for her help in establishing the clinical protocol and patient forms, Nathalie Duffey for her help in processing the samples, Mrs Melissa Rizza for reanalysis of samples, and Dr. Med. Sebastiano Semini for his help in identifying healthy donors. The authors wish to thank all patients and healthy donors for participating to this study.

\section{Authors' contributions}

Conceptualization, C.R. and A.F.-P.; methodology, S.C., M.B. C.R., and A.F.-P. formal analysis, S.C.; investigation, S.C., B.F, L.N., and M.B.; resources, A.B., A.C., A.CH., A.F.-P., P.T., A.S., L.N. M.B., and C.R.; writing-original draft preparation, S.C. and C.R..; writing-review and editing, A.F.P., C.R., S.C., and P.T.; supervision, S.C.; project administration, C.R. and A.F.-P.; funding acquisition, C.R. All authors have read and agreed to the published version of the manuscript.

\section{Funding}

This work was funded by the Swiss National Science Foundation, grant numbers 31003A_159824 and 31003A_179248 and the Medic Foundation to CR.

\section{Availability of data and materials}

The datasets used and/or analyzed during the current study are available from the corresponding author on reasonable request.

\section{Declarations}

Ethics approval and consent to participate

The study was approved by the Cantonal ethic commission for human research on Humans of Canton Ticino (CE 2967) and extended to VaudFribourg-Neuchâtel, Switzerland. All Patients and HDs gave written informed consent before study entry.

\section{Consent for publication}

All authors declare that they consent for the publication of the present manuscript.

Competing interests

The authors declare no conflict of interest. 


\section{Author details}

${ }^{1}$ Pathology, Department of Oncology, Microbiology and Immunology, Faculty of Science and Medicine, University of Fribourg, CH-1700 Fribourg, Switzerland. ${ }^{2}$ Central Laboratory, Hôpital Fribourgeois, CH-1700 Fribourg, Switzerland. ${ }^{3}$ Centro Oncologico Varini-Calderoni-Christinat, CH-6900 Lugano, Switzerland. ${ }^{4}$ Radiation Oncology Department, Clinica Luganese Moncucco, CH-6900 Lugano, Switzerland. ${ }^{5}$ Clinical Research unit, Clinica Luganese Moncucco, CH-6900 Lugano, Switzerland. 'Breast and Oncology Center, Hôpital Neuchatelois, CH-2300 La Chaux-de-Fonds, Switzerland. ${ }^{7}$ Present Address: Service de Radio-Oncologie, Hôpitaux Universitaires de Genève, $\mathrm{CH}-1205$ Geneva, Switzerland.

Received: 11 January 2021 Accepted: 25 May 2021 Published online: 05 June 2021

\section{References}

1. Malvezzi M, Bertuccio P, Levi F, La Vecchia C, Negri E. European cancer mortality predictions for the year 2012. Annal Oncol. 2012;23(4):1044-52 https://doi.org/10.1093/annonc/mds024.

2. Perou CM, Sørlie T, Eisen MB, van de Rijn M, Jeffrey SS, Rees CA, et al. Molecular portraits of human breast tumours. Nature. 2000;406(6797):74752. https://doi.org/10.1038/35021093.

3. Sotiriou C, Neo S-Y, McShane LM, Korn EL, Long PM, Jazaeri A, et al. Breast cancer classification and prognosis based on gene expression profiles from a population-based study. Proc Natl Acad Sci. 2003;100(18):10393-8. https:// doi.org/10.1073/pnas.1732912100.

4. Dawson S-J, Rueda OM, Aparicio S, Caldas C. A new genome-driven integrated classification of breast cancer and its implications. EMBO J. 2013; 32(5):617-28. https://doi.org/10.1038/emboj.2013.19.

5. Russnes HG, Lingjærde OC, Børresen-Dale A-L, Caldas C. Breast Cancer Molecular Stratification. Am J Pathol. 2017;187(10):2152-62. https://doi.org/1 0.1016/j.ajpath.2017.04.022.

6. Colozza M, de Azambuja E, Personeni N, Lebrun F, Piccart MJ, Cardoso F. Achievements in systemic therapies in the pregenomic era in metastatic breast cancer. The Oncol. 2007;12(3):253-70. https://doi.org/10.1634/ theoncologist.12-3-253.

7. Veronesi U, Cascinelli N, Mariani L, Greco M, Saccozzi R, Luini A, et al. Twenty-year follow-up of a randomized study comparing breast-conserving surgery with radical mastectomy for early breast cancer. N Engl J Med. 2002; 347(16):1227-32. https://doi.org/10.1056/NEJMoa020989.

8. Blichert-Toft M, Nielsen M, Düring M, Møller S, Rank F, Overgaard M, et al. Long-term results of breast conserving surgery vs. mastectomy for early stage invasive breast cancer: 20-year follow-up of the Danish randomized DBCG-82TM protocol. Acta Oncol. 2008;47(4):672-81. https://doi.org/10.1 080/02841860801971439.

9. Litière S, Werutsky G, Fentiman IS, Rutgers E, Christiaens M-R, Van Limbergen $E$, et al. Breast conserving therapy versus mastectomy for stage I-II breast cancer: 20 year follow-up of the EORTC 10801 phase 3 randomised trial. Lancet Oncol. 2012;13(4):412-9. https://doi.org/10.1016/S14 70-2045(12)70042-6.

10. Fisher B, Anderson S, Bryant J, Margolese RG, Deutsch M, Fisher ER, et al. Twenty-year follow-up of a randomized trial comparing total mastectomy, lumpectomy, and lumpectomy plus irradiation for the treatment of invasive breast cancer. N Engl J Med. 2002;347(16):1233-41. https://doi.org/10.1056/ NEJMoa022152.

11. Agarwal S, Pappas L, Neumayer L, Kokeny K, Agarwal J. Effect of breast conservation therapy vs mastectomy on disease-specific survival for earlystage breast cancer. JAMA Surg. 2014;149(3):267-74. https://doi.org/10.1001/ jamasurg.2013.3049.

12. Hwang ES, Lichtensztajn DY, Gomez SL, Fowble B, Clarke CA. Survival after lumpectomy and mastectomy for early stage invasive breast cancer: the effect of age and hormone receptor status. Cancer. 2013;119(7):1402-11. https://doi.org/10.1002/cncr.27795.

13. Hartmann-Johnsen OJ, Kåresen R, Schlichting E, Nygård JF. Survival is better after breast conserving therapy than mastectomy for early stage breast cancer: a registry-based follow-up study of Norwegian women primary operated between 1998 and 2008. Ann Surg Oncol. 2015;22(12):3836-45. https://doi.org/10.1245/s10434-015-4441-3.

14. Corradini S, Reitz D, Pazos M, Schönecker S, Braun M, Harbeck N, et al. Mastectomy or breast-conserving therapy for early breast cancer in real-life clinical practice: outcome comparison of 7565 cases. Cancers. 2019;11(2): 160. https://doi.org/10.3390/cancers11020160.

15. van Maaren MC, de Munck L, de Bock GH, Jobsen JJ, van Dalen T, Linn SC, et al. 10 year survival after breast-conserving surgery plus radiotherapy compared with mastectomy in early breast cancer in the Netherlands: a population-based study. Lancet Oncol. 2016;17(8):1158-70. https://doi.org/1 0.1016/S1470-2045(16)30067-5.

16. Effect of radiotherapy after breast-conserving surgery on 10-year recurrence and 15-year breast cancer death: meta-analysis of individual patient data for 10801 women in 17 randomised trials. Lancet. 2011;378(9804):1707-16.

17. Bleyer A, Welch HG. Effect of three decades of screening mammography on breast-cancer incidence. N Engl J Med. 2012;367(21):1998-2005. https://doi. org/10.1056/NEJMoa1206809.

18. van den Ende C, Oordt-Speets AM, Vroling H, van Agt HME. Benefits and harms of breast cancer screening with mammography in women aged 4049 years: A systematic review. Int J Cancer. 2017;141(7):1295-306. https:// doi.org/10.1002/ijc.30794.

19. Drooger JC, Hooning MJ, Seynaeve CM, Baaijens MHA, Obdeijn IM, Sleijfer S, et al. Diagnostic and therapeutic ionizing radiation and the risk of a first and second primary breast cancer, with special attention for BRCA1 and BRCA2 mutation carriers: A critical review of the literature. Cancer Treatment Rev. 2015;41(2):187-96. https://doi.org/10.1016/j.ctrv.2014.12.002.

20. Drukteinis JS, Mooney BP, Flowers Cl, Gatenby RA. Beyond mammography: new frontiers in breast cancer screening. Am J Med. 2013;126(6):472-9. https://doi.org/10.1016/j.amjmed.2012.11.025.

21. Sheng Z, Wang J, Li M, Luo X, Cai R, Zhang M. An overview protocol of biomarkers for breast cancer detection. Medicine. 2019;98(24):e16024. https://doi.org/10.1097/MD.0000000000016024.

22. Loke SY, Lee ASG. The future of blood-based biomarkers for the early detection of breast cancer. Eur J Cancer. 2018;92:54-68. https://doi.org/10.1 016/j.ejca.2017.12.025.

23. Hamam R, Hamam D, Alsaleh KA, Kassem M, Zaher W, Alfayez M, et al. Circulating microRNAs in breast cancer: novel diagnostic and prognostic biomarkers. Cell Death Dis. 2017;8(9):e3045. https://doi.org/10.1038/cddis.2 017.440.

24. Qiu J, Keyser B, Lin Z-T, Wu T. Autoantibodies as potential biomarkers in breast cancer. Biosensors. 2018;8(3):67. https://doi.org/10.3390/bios8030067.

25. Núñez C. Blood-based protein biomarkers in breast cancer. Clin Chim Acta. 2019;490:113-27. https://doi.org/10.1016/j.cca.2018.12.028.

26. Alix-Panabières $C$, Pantel K. Clinical applications of circulating tumor cells and circulating tumor DNA as liquid biopsy. Cancer Discov. 2016;6(5):47991. https://doi.org/10.1158/2159-8290.CD-15-1483.

27. Buono G, Gerratana L, Bulfoni M, Provinciali N, Basile D, Giuliano M, et al. Circulating tumor DNA analysis in breast cancer: is it ready for prime-time? Cancer Treatment Rev. 2019;73:73-83.

28. Duffy MJ, Evoy D, McDermott EW. CA 15-3: Uses and limitation as a biomarker for breast cancer. Clin Chim Acta. 2010:411(23-24):1869-74. https://doi.org/10.1016/j.cca.2010.08.039.

29. Hanahan D, Weinberg RA. Hallmarks of cancer: the next generation. Cell. 2011;144(5):646-74. https://doi.org/10.1016/j.cell.2011.02.013.

30. Lorusso G, Rüegg C. The tumor microenvironment and its contribution to tumor evolution toward metastasis. Histochem Cell Biol. 2008;130(6):1091103. https://doi.org/10.1007/s00418-008-0530-8.

31. Nagarajan D, McArdle S. Immune landscape of breast cancers. Biomedicines. 2018:6(1):20. https://doi.org/10.3390/biomedicines6010020.

32. Coffelt SB, de Visser KE. Systemic inflammation: cancer's long-distance reach to maximize metastasis. Oncolmmunology. 2016;5(2):e1075694. https://doi. org/10.1080/2162402X.2015.1075694.

33. Sleeman JP, Christofori G, Fodde R, Collard JG, Berx G, Decraene C, et al. Concepts of metastasis in flux: The stromal progression model. Semin Cancer Biol. 2012;22(3):174-86. https://doi.org/10.1016/j.semcancer.2012.02.007.

34. Cattin S, Fellay B, Pradervand S, Trojan A, Ruhstaller T, Rüegg C, et al. Bevacizumab specifically decreases elevated levels of circulating KIT+ CD11b+ cells and IL-10 in metastatic breast cancer patients. Oncotarget. 2016;7(10):11137-50. https://doi.org/10.18632/oncotarget.7097.

35. Schmittgen TD, Lee EJ, Jiang J, Sarkar A, Yang L, Elton TS and Chen C. Realtime PCR quantification of precursor and mature microRNA. Methods. 2008; 44(1):31-8.

36. Broxmeyer HE, Maze R, Miyazawa K, Carow C, Hendrie PC, Cooper S, et al. The kit receptor and its ligand, steel factor, as regulators of hemopoiesis. Cancer Cells. 1991;3(12):480-7. 
37. D'Arena G, Musto P, Cascavilla N, Carotenuto M. Thy-1 (CDw90) and c-kit receptor (CD117) expression on CD34+ hematopoietic progenitor cells: a five dimensional flow cytometric study. Haematologica. 1998;83(7):587-92.

38. Hou J, Zhang M, Ding Y, Wang X, Li T, Gao P, et al. Circulating CD14 ${ }^{+}$ $\mathrm{CD} 63{ }^{+} \mathrm{CD} 06^{+} \mathrm{M} 2$ monocytes are increased in patients with early stage of idiopathic membranous nephropathy. Mediat Inflamm. 2018;2018:1-10. https://doi.org/10.1155/2018/5270657.

39. Jatoi I, Benson JR, Kunkler I. Hypothesis: can the abscopal effect explain the impact of adjuvant radiotherapy on breast cancer mortality? NPJ Breast Cancer. 2018:4(1):8.

40. Cui Y, Li B, Pollom EL, Horst KC, Li R. Integrating radiosensitivity and immune gene signatures for predicting benefit of radiotherapy in breast cancer. Clin Cancer Res. 2018;24(19):4754-62. https://doi.org/10.1158/10780432.CCR-18-0825.

41. Lewin NL, Luetragoon T, Shamoun L, Oliva D, Andersson B-Å, Löfgren S, et al. The influence of adjuvant radiotherapy and single nucleotide polymorphisms on circulating immune response cell numbers and phenotypes of patients with breast cancer. Anticancer Res. 2019;39(9):495763. https://doi.org/10.21873/anticanres.13684.

42. Zielinski CC, Müller C, Kubista E, Staffen A, Eibl MM. Effects of adjuvant chemotherapy on specific and non-specific immune mechanisms. Acta Med Austriaca. 1990;17(1):11-4.

43. Nassar FJ, Chamandi G, Tfaily MA, Zgheib NK, Nasr R. Peripheral bloodbased biopsy for breast cancer risk prediction and early detection. Front Med. 2020;7:28. https://doi.org/10.3389/fmed.2020.00028.

44. Kuonen F, Laurent J, Secondini C, Lorusso G, Stehle J-C, Rausch T, et al. Inhibition of the Kit Ligand/c-Kit Axis Attenuates Metastasis in a Mouse Model Mimicking Local Breast Cancer Relapse after Radiotherapy. Clin Cancer Res. 2012;18(16):4365-74. https://doi.org/10.1158/1078-0432. CCR-11-3028.

45. Ko EC, Formenti SC. Radiation therapy to enhance tumor immunotherapy: a novel application for an established modality. Int J Radiat Biol. 2019;95(7): 936-9. https://doi.org/10.1080/09553002.2019.1623429.

46. Niknam S, Barsoumian HB, Schoenhals JE, Jackson HL, Yanamandra N, Caetano MS, et al. Radiation followed by OX40 stimulation drives local and abscopal antitumor effects in an anti-PD1-resistant lung tumor model. Clin Cancer Res. 2018;24(22):5735-43. https://doi.org/10.1158/1078-0432.CCR-1 7-3279.

47. Rodriguez-Ruiz ME, Rodriguez I, Garasa S, Barbes B, Solorzano JL, PerezGracia $J L$, et al. Abscopal effects of radiotherapy are enhanced by combined immunostimulatory mAbs and are dependent on CD8 T cells and crosspriming. Cancer Res. 2016;76(20):5994-6005. https://doi.org/10.1158/ 0008-5472.CAN-16-0549.

48. Yu W-D, Sun G, Li J, Xu J, Wang X. Mechanisms and therapeutic potentials of cancer immunotherapy in combination with radiotherapy and/or chemotherapy. Cancer Lett. 2019;452:66-70. https://doi.org/10.1016/j.ca nlet.2019.02.048

49. Poleszczuk JT, Luddy KA, Prokopiou S, Robertson-Tessi M, Moros EG, Fishman $\mathrm{M}$, et al. Abscopal benefits of localized radiotherapy depend on activated t-cell trafficking and distribution between metastatic lesions. Cancer Res. 2016;76(5):1009-18. https://doi.org/10.1158/0008-5472.CAN-1 5-1423.

50. Walker R, Poleszczuk J, Pilon-Thomas S, Kim S, Anderson AARA, Czerniecki $\mathrm{BJ}$, et al. Immune interconnectivity of anatomically distant tumors as a potential mediator of systemic responses to local therapy. Sci Rep. 2018;8(1): 9474. https://doi.org/10.1038/s41598-018-27718-1.

51. Gaipl US, Multhoff G, Scheithauer H, Lauber K, Hehlgans S, Frey B, et al. Kill and spread the word: stimulation of antitumor immune responses in the context of radiotherapy. Immunotherapy. 2014;6(5):597-610. https://doi. org/10.2217/imt.14.38.

52. Johnke RM, Edwards JM, Kovacs CJ, Evans MJ, Daly BM, Karlsson UL, et al. Response of T lymphocyte populations in prostate cancer patients undergoing radiotherapy: influence of neoajuvant total androgen suppression. Anticancer Res. 2005;25(4):3159-66.

53. Lissoni P, Brivio F, Fumagalli $L$, Messina G, Meregalli S, Porro G, et al. Effects of the conventional antitumor therapies surgery, chemotherapy, radiotherapy and immunotherapy on regulatory $T$ lymphocytes in cancer patients. Anticancer Res. 2009;29(5):1847-52

54. Rühle PF, Wunderlich R, Deloch L, Fournier C, Maier A, Klein G, et al. Modulation of the peripheral immune system after low-dose radon spa therapy: Detailed longitudinal immune monitoring of patients within the
RAD-ON01 study. Autoimmunity. 2017;50(2):133-40. https://doi.org/10.1080/ 08916934.2017.1284819.

\section{Publisher's Note}

Springer Nature remains neutral with regard to jurisdictional claims in published maps and institutional affiliations.
Ready to submit your research? Choose BMC and benefit from:

- fast, convenient online submission

- thorough peer review by experienced researchers in your field

- rapid publication on acceptance

- support for research data, including large and complex data types

- gold Open Access which fosters wider collaboration and increased citations

- maximum visibility for your research: over $100 \mathrm{M}$ website views per year

At BMC, research is always in progress.

Learn more biomedcentral.com/submissions 